\title{
Mitochondrial oxidative energy metabolism in guanethidine-induced sympathectomized ducklings
}

\author{
Younes Filali-Zegzouti ${ }^{1}$, Jean-Louis Rouanet ${ }^{2}$, Toufiq Fechtali ${ }^{3}$ and Damien Roussel ${ }^{2}$ \\ ${ }^{1}$ Université Moulay Ismail de Meknès, EPPE-FST, Errachidia, Morocco \\ ${ }^{2}$ Université de Lyon, UMR5023 Ecologie des Hydrosystèmes Naturels et Anthropisés, Université Lyon 1, ENTPE, CNRS, \\ Villeurbanne, France \\ ${ }^{3}$ Laboratoire de Physiologie et Ecophysiologie, Faculté des Sciences et Techniques, Mohammedia, Morocco
}

\begin{abstract}
Here we investigate the possible involvement of the sympathetic nervous system in the respiratory properties of intermyofibrillar and subsarcolemmal mitochondrial populations from heart and gastrocnemius muscles. Mitochondrial oxidative phosphorylation was assessed polarographically by using succinate (plus rotenone), and ascorbate plus N,N,N',N'-tetramethyl-p-phenyl-enediamine (plus antimycin) as respiratory substrates. We report that chronic chemical sympathectomy with guanethidine ( $150 \mathrm{mg} / \mathrm{kg}$, daily for 3 weeks) induced a marked decrease in whole body metabolic and heart rates, in plasma metabolites (fatty acids and glucose) and norepinephrine levels. Guanethidine treatment decreased mainly the oxidative phosphorylation capacity of subsarcolemmal mitochondria in heart, irrespective of the substrate used. In contrast, both mitochondrial populations were affected by the treatment in skeletal muscle. This suggests that sympathetic nervous system activity can alter the energetic status of muscle cells, and to some extent play a thermogenic role in birds.
\end{abstract}

Key words: Catecholamine - Birds - Sympathetic nervous system - Bioenergetics - Skeletal muscle physiology

\section{Introduction}

In cold environments, endothermic species have to produce more heat by sustaining active metabolism. In mammals, the sympathetic nervous system is the main controller of facultative heat production by activating brown adipose tissue. For birds, in the absence of brown fat, glucagon is the main thermogenic and lipolytic hormone involved in facultative thermogenesis (Duchamp et al. 1999). Nevertheless, studies have previously reported some calorigenic effects of catecholamines in birds, both in vivo (Barré and Rouanet 1983; Marmonier et al. 1997) and in vitro (Eldershaw et al. 1997; Marmonier et al. 1997). Interestingly, the thermogenic response of skeletal muscle to norepinephrine in vitro was found to increase in cold-acclimated and glucagon-treated ducklings (Marmonier et al. 1997), two experimental treat-

Correspondence to: Younes Filali-Zegzouti, Faculté des Sciences et Techniques, Université Moulay Ismail de Meknès, EPPE-FST BP 509, Errachidia, Morocco

E-mail: filali.younes@gmail.com ments enhancing regulatory thermogenesis in birds (Duchamp et al. 1999). In turn, guanethidine-induced chemical sympathectomy decreased the thermogenic effect of glucagon in ducklings (Filali-Zegzouti et al. 2005). Thus the stimulation of sympathetic nerve activity and hence the rise in norepinephrine concentrations in tissues might play a role in the modulation of regulatory thermogenesis in birds.

However, the thermogenic mechanisms of catecholamine remain unclear. Vascular control of tissue oxygen consumption may be one mechanism by which catecholamine could control thermogenesis in endotherms (Eldershaw et al. 1997; Marmonier et al. 1997). A second mechanism would involve direct or indirect action upon mitochondrial activity (Tapbergenov 1982). Indeed, a core requirement of the two fundamental thermogenic mechanisms, i.e. increased cellular ATP utilization and/or reduced ATP production efficiency, is mitochondrial oxidative phosphorylation activity, as mitochondria are the main sites of ATP production within cells. In this respect, alterations in mitochondrial functions by catecholamines in vivo have been previously reported in rats treated with either reserpine, a drug known to deplete 
catecholamine stores (Shukla et al. 2000) or propranolol (Katyare and Rajan 1991; Katyare 1994). In birds, it remains unclear whether in vivo, the activity of mitochondrial oxidative phosphorylation could be regulated by the sympathetic nervous system.

Chronic oral administration of guanethidine in ducklings has been reported to produce an efficient sympathectomy (Filali-Zegzouti et al. 2005), as previously shown in rats following intraperitoneal or subcutaneous infusion (Romanyshyn and Clarke 1976; Picklo 1997; Villanueva et al. 2003). By using guanethidine, we aimed to investigate the possibility that the sympathetic nervous system might modulate mitochondrial respiratory properties of heart and skeletal muscles in ducklings. We also measured concomitant changes in whole-body metabolic activity as well as in blood levels of catecholamines, glucose and free fatty acids.

\section{Materials and Methods}

\section{Guanethidine treatment}

Male Muscovy ducklings (Cairina moschata, pedigree R 31, INRA, France) were obtained from a commercial stockbreeder (Ets Grimaud, France). Ducklings were fed ad libitum with a commercial mash (Sanders, France) and had free access to water. The birds were cared for under the French Code of Practice for the Care and Use of Animals for Scientific Purposes and the experimental protocol was approved by the French Ministry of Agriculture Ethics Committee (Animals). Between the ages of 1 week and 6 weeks, ducklings were caged in groups of 8 at $25^{\circ} \mathrm{C}$ in a constant photoperiod (8:16 light:dark). From the age of 2 weeks, ducklings were treated with guanethidine (Ismeline+, CIBA France; $150 \mathrm{mg} / \mathrm{kg}$ per-os) daily at 8 a.m. for 3 weeks $(n=6)$, as described previously (Filali-Zegzouti et al. 2005). The control group $(n=8)$ received saline $(\mathrm{NaCl}$ $0.9 \%$, per-os) daily at 8 a.m.

\section{Metabolic and heart rates measurements}

Metabolic rate was measured in vivo by indirect calorimetry using an open-circuit, as described previously (Barré et al. 1987). The rates of $\mathrm{O}_{2}$ and $\mathrm{CO}_{2}$ production were calculated according to the equation of Depocas and Hart (1957). Electrocardiograms (ECGs) were obtained using two subcutaneous electrodes (Stabilohmo 110, nichrom, $0.12 \mathrm{~mm}$ diam, Johnson Mattey Metals, UK) in the pectoral muscle. To obtain metabolic steady-state and thermal equilibrium, the control or guanethidine ducklings were left sitting in the dark in a thermostatic chamber at thermoneutrality $\left(25^{\circ} \mathrm{C}\right)$ for an initial $120 \mathrm{~min}$ adjustment period before the experiment started. The experiments were performed during the day time (between 8 a.m. and 7 p.m.) on ducklings fasted for 14 h.
Blood sampling protocol and biochemical assay

For blood sampling, catheters were chronically implanted. All surgical preparations were performed under anaesthesia with halothane ( $2.5 \%$ in air) the week before the investigations. A polyethylene catheter $(0.96-0.58 \mathrm{~mm}$, Biotrol) was fitted with a silastic tip of about $1 \mathrm{~cm}$, and subsequently inserted into the right carotid for blood sampling. A length of $10 \mathrm{~cm}$ tubing terminating near the right brachial artery was held in place with a silk ligature. The catheter was flushed with heparinized saline twice a day to prevent clotting. In order to minimize the stress of surgery, endogenous plasma levels were measured 2 days after catheter implantation. On the day of the experiment, the catheter was extended outside the chamber to avoid unspecific stress during blood sampling. Blood samples $(0.5 \mathrm{ml})$ were collected in polyethylene vials containing heparin $(5 \mu \mathrm{l})$ and immediately centrifuged at $1,000 \times g$ for $5 \mathrm{~min}\left(4^{\circ} \mathrm{C}\right)$. The supernatants were stored at $-80^{\circ} \mathrm{C}$ prior to biochemical analysis. Endogenous plasma norepinephrine, epinephrine and dopamine were assayed simultaneously by high-performance liquid chromatography coupled with electrochemical detection (Sagnol et al. 1990). Plasma glucose and glycerol were determined enzymatically using reagents from Boehringer Mannheim (Germany). Plasma free fatty acids and glucose were measured enzymatically using a kit from Biolyon (France).

\section{Mitochondrial isolation and activity}

Gastrocnemius and heart muscles were rapidly dissected, weighed, placed into ice-cold isolation buffer and homogenized with a Potter-Elvehjem homogenizer. Intermyofibrillar (IFM) and subsarcolemmal (SSM) mitochondria were isolated from gastrocnemius and heart muscles in a buffer containing $100 \mathrm{mM}$ sucrose, $50 \mathrm{mM} \mathrm{KCl,} 5 \mathrm{mM}$ EGTA and $50 \mathrm{mM}$ Tris/ $\mathrm{HCl}, \mathrm{pH} 7.4$ at $4^{\circ} \mathrm{C}$ as described previously (Roussel et al. 1998).

The rates of oxygen consumption were measured with a Clark oxygen electrode in a glass cell of $1.5 \mathrm{ml}$ volume with constant stirring, as described previously (Roussel et al. 1998, 2000). Respiratory substrates were succinate $(10 \mathrm{mM})$ in the presence of $5 \mu \mathrm{M}$ rotenone, or $8 \mathrm{mM}$ ascorbate plus $0.6 \mathrm{mM}$ $N, N, N^{\prime}, N^{\prime}$-tetramethyl-p-phenylenediamine (TMPD) in the presence of $5 \mu \mathrm{M}$ antimycin. The method of Estabrook (1967) was used for the calculation of respiratory states 4 and 3 and the respiratory control ratio (RCR). The ADPto-O ratio was calculated by measuring the total oxygen consumed during the phosphorylation of a pulse of $100 \mu \mathrm{M}$ ADP (Estabrook 1967). The efficiency of the mitochondrial oxidative phosphorylation process was assessed by the following parameters: (1) the ADP-to-O ratio; (2) the RCR, the ratio of oxygen consumed in the presence of ADP to that after phosphorylation of ADP; (3) the oxidative phosphorylation 
rate (OPR), calculated as the product of the ADP-to-O ratio and the oxygen consumed during state 3 respiration and expressed in nmol of ATP produced during state 3 per min per mg of mitochondrial protein (Edoute et al. 1979).

\section{Data presentation and statistical analysis}

Data are reported as means \pm S.E.M. The effect of guanethidine treatment (guanethidine versus control ducklings) was analysed using two-way analysis of variance with post-hoc comparisons performed with the Scheffe F tests. The level of significance was set at $p<0.05$.

\section{Results}

\section{Body weight and organ mass}

The present data show that the body mass of guanethidine ducklings was significantly lower than control birds $(p<$ 0.05). Three weeks of chronic guanethidine treatment induced a significant decrease in gastrocnemius muscle $(-44 \%$, $p<0.001)$, heart $(-48 \%, p<0.01)$ and liver $(-42 \%, p<0.01)$ mass (Table 1).

\section{Metabolic and heart rate, body temperature and plasma metabolites}

Resting metabolic rate $(-20 \%, p<0.01)$ and heart rate $(-10 \%$, $p<0.05)$ were lower in guanethidine compared to control ducklings. In contrast, guanethidine treatment failed to alter body temperature in these ducklings (Table 2). Furthermore, plasma concentrations of glycerol were not altered by chronic guanethidine treatment, whereas glucose $(-29 \%, p<0.05)$ and free fatty acids $(-26 \%, p<0.05)$ levels were significantly lower in guanethidine than in control ducklings (Table 2).

\section{Plasma catecholamines}

Chronic guanethidine treatment produced a considerable decrease in the plasma concentration of norepinephrine in guanethidine compared with control ducklings $(-26 \%$,

Table 1. Body weight and organ masses in control and guanethidine-treated ducklings

\begin{tabular}{lcc}
\hline & Control & Guanethidine \\
\hline Body weight $(\mathrm{g})$ & $1190 \pm 71$ & $907 \pm 67^{\star}$ \\
Gastrocnemius muscle $(\mathrm{g})$ & $20.3 \pm 1.1$ & $11.4 \pm 1.0^{* * *}$ \\
Heart $(\mathrm{g})$ & $6.7 \pm 0.6$ & $3.5 \pm 0.5^{* *}$ \\
Liver $(\mathrm{g})$ & $39.6 \pm 2.9$ & $22.8 \pm 2.4^{* *}$ \\
\hline
\end{tabular}

Values are means \pm S.E.M. from $5-8$ animals. ${ }^{\star} p<0.05 ;{ }^{* *} p<0.01$; ${ }^{* * *} p<0.001$ significantly different from control ducklings.
Table 2. Metabolic and heart rates, body temperature, and plasma metabolites in control and guanethidine-treated ducklings

\begin{tabular}{lcc}
\hline Parameter & Control & Guanethidine \\
\hline Metabolic rate $(\mathrm{W} / \mathrm{kg})$ & $5.5 \pm 0.1$ & $4.4 \pm 0.2^{\star *}$ \\
Heart rate (beats/min) & $190 \pm 5$ & $171 \pm 7^{\star}$ \\
Body temperature $\left({ }^{\circ} \mathrm{C}\right)$ & $40.9 \pm 0.3$ & $40.1 \pm 0.5$ \\
Glucose $(\mathrm{mM})$ & $10.4 \pm 0.3$ & $7.3 \pm 0.5^{\star}$ \\
Glycerol $(\mathrm{mM})$ & $0.21 \pm 0.02$ & $0.17 \pm 0.02$ \\
Free fatty acids $(\mathrm{mM})$ & $0.78 \pm 0.04$ & $0.57 \pm 0.05^{\star}$ \\
Norepinephrine $(\mathrm{nM})$ & $4.4 \pm 0.3$ & $3.2 \pm 0.4^{\star}$ \\
Epinephrine $(\mathrm{nM})$ & $0.71 \pm 0.03$ & $0.57 \pm 0.07$ \\
Dopamine $(\mathrm{nM})$ & $0.23 \pm 0.03$ & $0.29 \pm 0.05$ \\
\hline
\end{tabular}

Values are means \pm S.E.M. from $5-8$ animals. ${ }^{*} p<0.05 ;{ }^{* *} p<0.01$ significantly different from control ducklings.

$p<0.05$ ), whereas a slight but not statistically significant $20 \%$ decrease was noted in the plasma level of epinephrine in guanethidine ducklings (Table 2). The plasma concentration of dopamine was not different between groups (Table 2).

\section{Mitochondrial oxidative phosphorylation}

Table 3 reports the respiratory parameters of intermyofibrillar and subsarcolemmal mitochondria isolated from the gastrocnemius and heart muscles of control and guanethidine-treated ducklings. In skeletal muscle, guanethidine treatment decreased the oxidative phosphorylation rates (state 3 respiration and OPR values) in IFM respiring on ascorbate/TMPD $(-26 \%, p<0.05)$ or succinate $(-15 \%$, $p=0.06)$. The basal non-phosphorylating respiration rates (state 4) had also decreased in IFM respiring on ascorbate/ TMPD $(-27 \%, p<0.05)$ or succinate $(-30 \%, p=0.05)$. There was no guanethidine effect on the ADP-to-O ratio in skeletal muscle IFM populations, whatever the respiratory substrate used. Guanethidine treatment also elicited a significant decrease in phosphorylation activity (OPR values) in skeletal muscle SSM with succinate, an effect which was due to a tendency of state 3 respiration and oxidative phosphorylation efficiency to decrease. In heart muscle, guanethidine treatment decreased both respiratory (states 3 and 4 ) and phosphorylation (OPR values) activities in SSM respiring on succinate or ascorbate/TMPD (Table 3). In contrast, there were no significant effects of treatment on respiratory parameters in heart IFM with either succinate or ascorbate/TMPD (Table 3).

\section{Discussion}

In control ducklings, concentrations of arterial plasma norepinephrine, epinephrine and dopamine were comparable to those previously reported for domestic ducks (Wilson 
Table 3. Effects of guanethidine treatment on respiratory parameters of muscle mitochondria

\begin{tabular}{|c|c|c|c|c|c|c|}
\hline \multirow{2}{*}{ Tissue } & \multirow{2}{*}{$\begin{array}{l}\text { Respiratory } \\
\text { substrates }\end{array}$} & \multirow{2}{*}{ Parameter } & \multicolumn{2}{|c|}{ Intermyofibrillar mitochondria } & \multicolumn{2}{|c|}{ Subsarcolemmal mitochondria } \\
\hline & & & Control & Guanethidine & Control & Guanethidine \\
\hline \multirow{8}{*}{ Gastrocnemius } & \multirow{4}{*}{$\begin{array}{l}\text { Succinate } \\
\text { (+rotenone) }\end{array}$} & State 3 & $121 \pm 9$ & $99 \pm 6$ & $45 \pm 5^{\dagger}$ & $39 \pm 3^{\dagger}$ \\
\hline & & State 4 & $33 \pm 5$ & $23 \pm 2$ & $14 \pm 2^{\dagger}$ & $21 \pm 4$ \\
\hline & & ADP-to-O & $1.18 \pm 0.06$ & $1.26 \pm 0.03$ & $0.91 \pm 0.10^{\dagger}$ & $0.76 \pm 0.08^{\dagger}$ \\
\hline & & OPR & $142 \pm 12$ & $126 \pm 9$ & $39 \pm 3^{\dagger}$ & $29 \pm 3^{\dagger *}$ \\
\hline & \multirow{4}{*}{$\begin{array}{l}\text { Ascorbate/TMPD } \\
\text { (+antimycin) }\end{array}$} & State 3 & $302 \pm 22$ & $227 \pm 15^{*}$ & n.d. & n.d. \\
\hline & & State 4 & $220 \pm 25$ & $160 \pm 10^{*}$ & n.d. & n.d. \\
\hline & & ADP-to-O & $0.73 \pm 0.03$ & $0.71 \pm 0.02$ & n.d. & n.d. \\
\hline & & OPR & $220 \pm 22$ & $161 \pm 10^{*}$ & n.d. & n.d. \\
\hline \multirow{8}{*}{ Heart } & \multirow{4}{*}{$\begin{array}{l}\text { Succinate } \\
\text { (+rotenone) }\end{array}$} & State 3 & $129 \pm 9$ & $127 \pm 9$ & $121 \pm 7$ & $77 \pm 3^{\dagger x}$ \\
\hline & & State 4 & $39 \pm 3$ & $34 \pm 5$ & $28 \pm 1^{\dagger}$ & $18 \pm 3^{\dagger *}$ \\
\hline & & ADP-to-O & $1.28 \pm 0.07$ & $1.28 \pm 0.11$ & $1.27 \pm 0.04$ & $1.16 \pm 0.14$ \\
\hline & & OPR & $164 \pm 14$ & $160 \pm 7$ & $153 \pm 8$ & $89 \pm 12^{\dagger *}$ \\
\hline & \multirow{4}{*}{$\begin{array}{l}\text { Ascorbate/TMPD } \\
\text { (+antimycin) }\end{array}$} & State 3 & $281 \pm 24$ & $250 \pm 13$ & $273 \pm 12$ & $147 \pm 1^{\star}$ \\
\hline & & State 4 & $196 \pm 14$ & $179 \pm 6$ & $186 \pm 6$ & $120 \pm 2^{\star}$ \\
\hline & & ADP-to-O & $0.82 \pm 0.04$ & $0.83 \pm 0.03$ & $0.77 \pm 0.03$ & $0.65 \pm 0.02$ \\
\hline & & OPR & $226 \pm 15$ & $207 \pm 3$ & $210 \pm 12$ & $96 \pm 3^{*}$ \\
\hline
\end{tabular}

Mitochondria were isolated from gastrocnemius and heart muscles as described in the "Materials and Methods" section. Respiration rates were determined with succinate (in the presence of rotenone) or ascorbate/TMPD (in the presence of antimycin) as respiratory substrates. Values are means \pm S.E.M. for 4-8 animals excepted guanethidine heart mitochondria respiring on ascorbate/TMPD where $n=2$. Respiration rates (State 3 and State 4 ) are expressed in nmol of oxygen/min per $\mathrm{mg}$ of protein. OPR, oxidative phosphorylation rate (nmol ATP/min per mg of protein). ${ }^{*} p<0.05$, significantly different from control within the same mitochondrial population. ${ }^{\dagger} p<0.05$, significantly different from intermyofibrillar mitochondria within the same experimental groups. n.d., not determined.

1984; Filali-Zegzouti et al. 2000; Abdelmelek et al. 2001). In ducklings, treatment of guanethidine for three weeks did not induce significant changes in plasma dopamine and epinephrine levels. In contrast, plasma levels of norepinephrine were markedly reduced in guanethidine birds. In terms of the source of circulating catecholamines in birds, Rome and Bell (1983) have shown that norepinephrine alone constitutes the predominant sympathetic neurotransmitter in fowl. In rats, Villanueva et al. (2003) have shown that chemical sympathectomy with guanethidine selectively blocks the release of norepinephrine from the postganglionic nerve terminals, leading to a decrease in norepinephrine concentrations in several tissues, including skeletal muscles (Navegantes et al. 1999; Villanueva et al. 2003). Similarly, chronic guanethidine treatment leads to a fifty percent drop in norepinephrine concentrations in the heart and skeletal muscles of ducklings (Filali-Zegzouti et al. 2000). Although the molecular and cellular mechanisms for this drop in plasma and tissues levels remain unclear, our data confirm that the oral administration of guanethidine in ducklings results in an effective sympathectomy (Filali-Zegzouti et al. 2000).

Chronic guanethidine treatment is known to cause the inhibition of oxidative phosphorylation in sympathetic neurons in vivo (Johnson and Manning 1984) or in mitochondria isolated from heart, brain or liver in vitro (Malmquist and Oates 1968; Ferreira et al. 1985). Here, we report that three weeks of guanethidine treatment in vivo altered the oxidative phosphorylation activities of mitochondria isolated from skeletal muscle or heart. We also found that both mitochondrial populations from skeletal muscle were affected by guanethidine-induced sympathectomy, while only subsarcolemmal mitochondria were strongly altered by the treatment in heart muscle. The larger reduction in muscle oxidative phosphorylation activity with ascorbate/TMPD as compared with succinate suggests that cytochrome-c oxidase might be the main component of the respiratory chain affected by this guanethidine-induced adrenergic blockade. Interestingly, it has been shown that cytochromec oxidase activity, as well as cytochrome c content, are the first elements of the electron transport chain to be affected during the adjustment of muscle metabolism in response to either endurance training or chronic unloading (Essig 1996; Roussel et al. 2000; Singh and Hood 2010). These results are of interest because they suggest that the lower guanethidineinduced mitochondrial oxidative phosphorylation capacity would be due to decreased muscle metabolism. Furthermore, the regional differences in mitochondrial adaptation could be caused by localized biochemical and functional differences in energy-consuming mechanisms, namely muscle contraction for IFM and the active transport of metabolites or calcium through the sarcolemma for SSM (Müller 1976; Roussel et al. 2000). In the present study, the overall metabolic activ- 
ity of a functioning heart was significantly decreased following three weeks of guanethidine treatment. Therefore, the specific down-regulation of metabolic activity in SSM suggests that guanethidine-induced sympathectomy would mainly decrease energy demanding processes that operate through or just beneath the cardiac muscle sarcolemma. In turn, IFM remained unaffected in beating hearts due to the maintenance of regular contractile activity.

The fact that both mitochondrial populations were affected in skeletal muscle might suggest that both metabolic and contractile activities decreased in guanethidine-treated ducklings. This hypothesis is supported by some results suggesting that interactions between the vascular and metabolic actions of catecholamines stimulate skeletal muscle oxygen consumption in birds (Eldershaw et al. 1997; Marmonier et al. 1997; Joubert et al. 2010, 2011). Nevertheless, $\beta_{2}$-adrenergic agents have also been described as increasing skeletal muscle mass in birds and many other species, by altering protein turnover (Morgan et al. 1989; Ji and Orcutt 1991; Navegantes et al. 1999). For instance, a guanethidine-induced adrenergic blockade over a few days decreased protein synthesis and transiently increased proteolysis in the skeletal muscle of rats (Navegantes et al. 1999, 2003, 2004). By lowering net protein synthesis in skeletal muscle, such changes in protein metabolism could explain the muscle atrophy elicited by three weeks of guanethidine treatment in ducklings, but also the down-regulation of oxidative phosphorylation capacity in both mitochondrial populations. It is interesting to note that such alterations in muscle mass and mitochondrial activity resemble those reported in animal models of mechanical unloading, in which skeletal muscle inactivity induced a decrease in net protein synthesis in association with muscle atrophy and a lower mitochondrial oxidative activity (Momken et al. 2011). These data reinforce the idea that guanethidine treatment could decrease the contractile activity of skeletal muscle in ducklings. Overall and contrary to the in vitro studies (Malmquist and Oates 1968; Ferreira et al. 1985), the present variations in muscle mitochondrial activities would be caused more by mitochondrial adjustment to a chemical sympathectomy-induced chronic decrease in the basal activity of organs rather than being a direct effect of guanethidine upon mitochondria, in agreement with results reported in reserpine-treated rats (Shukla et al. 2000). Although the molecular signalling pathway involved in the observed effects of chemical sympathectomy upon muscle mitochondrial activities remains to be investigated, the proposed hypothesis deserves further study.

In this study, the chronic guanethidine treatment induced a decrease in the plasma levels of metabolites. Since skeletal muscle is the main thermogenic organ in cold-acclimated or in glucagon-treated ducklings (Duchamp and Barré 1993; Duchamp et al. 1999), the present decrease in mitochondrial muscle activity, in association with a decrease in the plasma levels of glucose and fatty acids, may in part explain why guanethidine-treated ducklings exhibit a lower thermogenic response to glucagon infusion (Filali-Zegzouti et al. 2005). As previously reported in rat (Ernst et al. 1982), it can be inferred from these data (e.g. decreases in heart rate, skeletal muscle respiratory capacity and circulating metabolites) that guanethidine-induced sympathectomy might reduce the maximal aerobic capacity (VO2max) of ducklings. This would in turn impact the amount of energy that ducklings can allocate to thermogenic processes. Altogether these data suggest that the sympathetic nervous system (norepinephrine) may modulate facultative thermogenesis in birds. This idea is also in line with recently published data suggesting that the beta-adrenergic system would be involved in regulating the expression of avian uncoupling protein (Joubert et al. 2010, 2011), a mitochondrial protein that has been linked to the intensity of regulatory thermogenesis in cold-acclimated ducklings (Teulier et al. 2010). Whether guanethidine-treated ducklings displayed a lower expression of avian UCP is currently not known but deserves further study. In conclusion, the present study reports that long-term guanethidine treatment decreases tissue mass, circulating energy substrates and mitochondrial muscle oxidative phosphorylation activities. These alterations would explain, at least in part, the reduced resting metabolic rate and glucagon-induced regulatory thermogenesis reported in sympathectomized ducklings.

\section{References}

Abdelmelek H., Fechtali T., Filali-Zegzouti Y., Rouanet J. L., CottetEmard J. M., Pequignot J. M., Barre H. (2001): Responsiveness of plasma catecholamines to intracerebroventricular injection of glucagon in Muscovy ducklings. J. Neural. Transm. 108, 793-801

http://dx.doi.org/10.1007/s007020170029

Barré H., Rouanet J. L. (1983): Calorigenic effect of glucagon and catecholamines in king penguin chicks. Am. J. Physiol. 244, R758-763

Barré H., Cohen-Adad F., Rouanet J. L. (1987): Two daily glucagon injections induce nonshivering thermogenesis in Muscovy ducklings. Am. J. Physiol. 252, E616-620

Barré H., Berne G., Brebion P., Cohen-Adad F., Rouanet J. L. (1989): Loose-coupled mitochondria in chronic glucagon-treated hyperthermic ducklings. Am. J. Physiol. 256, R1192-1199

Depocas F., Hart J. S. (1957): Use of the Pauling oxygen analyzer for measurement of oxygen consumption of animals in opencircuit systems and in a short-lag, closed circuit apparatus. Appl. Physiol. 10, 388-392

Duchamp C., Barré H. (1993): Skeletal muscle as the major site of nonshivering thermogenesis in cold-acclimated ducklings. Am. J. Physiol. 265, R1076-1083

Duchamp C., Marmonier F., Denjean F., Lachuer J., Eldershaw T. P. D., Rouanet J. L., Morales A., Meister R., Bénistant C., Roussel 
D., Barré H. (1999): Regulatory, cellular and molecular aspects of avian muscle nonshivering thermogenesis. Ornis Fenn. 76, 151-165

Edoute Y., Kotzé J. C. N., Lochner A. (1979): Oxidative phosphorylation rate: an index for evaluation of mitochondrial function in myocardial ischaemia. J. Mol. Cell. Cardiol. 11, 831-833 http://dx.doi.org/10.1016/0022-2828(79)90408-5

Eldershaw T. P. D., Duchamp C., Ye J., Clark M. G., Colqhoun E. Q. (1997): Potential non-shivering thermogenesis in perfused chicken (Gallus domesticus) muscle. Comp. Biochem. Physiol. 117A, 545-554

Ernst S. B., Mullin W. J., Herrick R. E., Baldwin K. M. (1982): Exercise and cardiac performance capacity in rats with partial sympathectomy. J. Appl. Physiol. 53, 242-246

Essig D. A. (1996): Contractile activity-induced mitochondrial biogenesis in skeletal muscle. Exerc. Sport Sci. Rev. 24, 289-319 http://dx.doi.org/10.1249/00003677-199600240-00012

Estabrook R. W. (1967): Mitochondrial respiratory control and the polarographic measurement of ADP/O ratios. Methods Enzymol. 10, 41-47 http://dx.doi.org/10.1016/0076-6879(67)10010-4

Ferreira J., Gil L., Stutzin A., Orrego F. (1985): Effects of guanethidine on electron transport and proton movements in rat heart, brain and liver mitochondria. Biochem. Pharmacol. 34, $2507-2512$ http://dx.doi.org/10.1016/0006-2952(85)90534-9

Filali-Zegzouti Y., Abdelmelek H., Rouanet J. L., Cottet-Emard J. M., Pequignot J. M., Barre H. (2000): Involvement of the catecholaminergic system in glucagon-induced thermogenesis in Muscovy ducklings (Cairina moschata). Pflügers Arch. 441, 275-280

http://dx.doi.org/10.1007/s004240000409

Filali-Zegzouti Y., Abdelmelek H., Rouanet J. L., Cottet-Emard J. M., Pequignot J. M., Barré H. (2005): Role of catecholamines in glucagon-induced thermogenesis. J. Neural. Transm. 112, 481-489 http://dx.doi.org/10.1007/s00702-004-0199-7

Ji S. Q., Orcutt M. W. (1991): Effects of the beta-adrenergic agonist isoproterenol on protein accretion, synthesis, and degradation in primary chicken muscle cell cultures. J. Anim. Sci. 69, 2855-2864

Johnson E. M., Manning P. T. (1984): Guanethidine-induced destruction of sympathetic neurons. Int. Rev. Neurobiol. 25, $1-37$ http://dx.doi.org/10.1016/S0074-7742(08)60676-5

Joubert R., Métayer-Coustard S., Swennen Q., Sibut V., Crochet S., Cailleau-Audouin E., Buyse J., Decuypere E., Wrutniak-Cabello C., Cabello G., Tesseraud S., Collin A. (2010): The beta-adrenergic system is involved in the regulation of the expression of avian uncoupling protein in the chicken. Domest. Anim. Endocrinol. 38, 115-125 http://dx.doi.org/10.1016/j.domaniend.2009.08.002

Joubert R., Métayer-Coustard S., Crochet S., Cailleau-Audouin E., Dupont J., Duclos M. J., Tesseraud S., Collin A. (2011): Regulation of the expression of the avian uncoupling protein 3 by isoproterenol and fatty acids in chick myoblasts: possible involvement of AMPK and PPARa? Am. J. Physiol. 301, R201-208
Katyare S. S., Rajan R. R. (1991): Altered energy coupling in rat heart mitochondria following in vivo treatment with propranolol. Biochem. Pharmacol. 42, 617-623 http://dx.doi.org/10.1016/0006-2952(91)90325-Y

Katyare S. S. (1994): Effect of in vivo propranolol treatment on oxidative energy metabolism in rat liver and kidney mitochondria. Indian J. Biochem. Biophys. 31, 403-406

Malmquist J., Oates J. A. (1968): Effects of adrenergic neuronblocking guanidine derivatives on mitochondrial metabolism. Biochem. Pharmacol. 17, 1845-1854 http://dx.doi.org/10.1016/0006-2952(68)90100-7

Marmonier F., Duchamp C., Cohen-Adad F., Eldershaw T. P. D., Barré H. (1997): Hormonal control of thermogenesis in perfused muscle of Muscovy ducklings. Am. J. Physiol. 273, R1638-R1648

Momken I., Stevens L., Bergouignan A., Desplanches D., Rudwill F., Chery I., Zahariev A., Zahn S., Stein T. P., Sebedio J. L., PujosGuillot E., Falempin M., Simon C., Coxam V., Andrianjafiniony T., Gauquelin-Koch G., Picquet F., Blanc S. (2011): Resveratrol prevents the wasting disorders of mechanical unloading by acting as a physical exercise mimetic in the rat. FASEB J. 25, 3646-3660 http://dx.doi.org/10.1096/fj.10-177295

Morgan J. B., Jones S. J., Calkins C. R. (1989): Muscle protein turnover and tenderness in broiler chickens fed cimaterol. J. Anim. Sci. 67, 2646-2654

Müller W. (1976): Subsarcolammal mitochondria and capillarization of soleus muscle fibers in young rats subjected to an endurance training. Cell tissue Res. 174, 367-389

http://dx.doi.org/10.1007/BF00220682

Navegantes L. C. C., Resano N. M. Z., Migliorini R. H., Kettelhut I. C. (1999): Effect of guanethidine-induced adrenergic blockade on the different proteolytic systems in rat skeletal muscle. Am. J. Physiol. 277, E883-889

Navegantes L. C. C., Machado C. R., Resano N. M. Z., Migliorini R. H., Kettelhut I. C. (2003): $\beta 2$-Agonists and cAMP inhibit protein degradation in isolated chick (Gallus domesticus) skeletal muscle. Brit. Poult. Sci. 44, 149-154 http://dx.doi.org/10.1080/0007166031000085355

Navegantes L. C. C., Resano N. M. Z., Baviera A. M., Migliorini R. H., Kettelhut I. C. (2004): Effect of sympathetic denervation on the rate of protein synthesis in rat skeletal muscle. Am. J. Physiol. 286, E642-647

Picklo J. M. (1997): Methods of sympathetic degeneration and alteration. J. Auton. Nerv. Syst. 62, 111-125 http://dx.doi.org/10.1016/S0165-1838(96)00121-X

Romanyshyn W. M., Clarke D. E. (1976): Chronic guanethidine and adrenal medullary function in the rat. J. Pharm. Pharmacol. 28, 785-786 http://dx.doi.org/10.1111/j.2042-7158.1976.tb04052.x

Rome A., Bell C. (1983): Catecholamines in the sympathetic nervous system of the domestic fowl. J. Auton. Nerv. Syst. 4, 331-342 http://dx.doi.org/10.1016/0165-1838(83)90028-0

Roussel D., Rouanet J. L., Duchamp C., Barré H. (1998): Effects of cold acclimation and palmitate on energy coupling in duckling skeletal muscle mitochondria. FEBS Lett. 439, 258-262 http://dx.doi.org/10.1016/S0014-5793(98)01382-9

Roussel D., Lhenry F., Ecochard L., Sempore B., Rouanet J. L., Favier R. (2000): Differential effects of endurance training and creatine 
depletion on regional mitochondrial adaptations in rat skeletal muscle. Biochem. J. 350, 547-553

http://dx.doi.org/10.1042/0264-6021:3500547

Sagnol M., Claustre J. M., Cottet-Emard J. M., Pequignot N., Fellmann J., Coudert J., Peyrin L. (1990): Plasma free and sulphated catecholamines after ultra-long exercise and recovery. Eur. J. Appl. Physiol. 60, 91-97

http://dx.doi.org/10.1007/BF00846027

Shukla V. H., Dave K. R., Katyare S. S. (2000): Effect of catecholamine depletion on oxidative energy metabolism in rat liver, brain and heart mitochondria: use of reserpine. Comp. Biochem. Physiol. 127C, 79-90

Singh K., Hood D. A. (2010): Effect of denervation-induced muscle disuse on mitochondrial protein import. Am. J. Physiol. 300, C138-145 http://dx.doi.org/10.1152/ajpcell.00181.2010

Tapbergenov S. O. (1982): Catecholamine metabolism and mitochondrial enzyme activity. Vopr. Med. Khim. 28, 52-58
Teulier L., Rouanet J. L., Letexier D., Romestaing C., Belouze M., Rey B., Duchamp C., Roussel D. (2010): Cold-acclimation-induced non-shivering thermogenesis in birds is associated with upregulation of avian UCP but not with innate uncoupling or altered ATP efficiency. J. Exp. Biol. 213, 2476-2482 http://dx.doi.org/10.1242/jeb.043489

Villanueva I., Pinon M., Quevedo-Corona L., Martinez-Olivares R., Racotta R. (2003): Epinephrine and dopamine colocalization with norepinephrine in various peripheral tissues: guanethidine effects. Life Sci. 73, 1645-1653 http://dx.doi.org/10.1016/S0024-3205(03)00491-0

Wilson J. X. (1984): Conjugated catecholamines in birds. Neurosci. Lett. 51, 337-340 http://dx.doi.org/10.1016/0304-3940(84)90399-9

Received: June 5, 2013

Final version accepted: August 21, 2013 